\title{
Study on Effect of Environmental Quality of Jiangsu Province on Economic Growth
}

\author{
Based on the Kuznets Curve
}

\author{
Zhiqiang Sun \\ Jincheng College \\ Nanjing University of Aeronautics and Astronautics \\ Nanjing, Jiangsu, China 210000
}

\begin{abstract}
EKC hypothesis means the environmental quality shall be worsened gradually in the early stage of economic development and improved gradually when the economic development has reached a certain level, that is, the inverted $U$ shaped relationship is formed between the environmental pressure and the economic growth. The econometric model was set up between the economic development and emission of industrial pollution in accordance with the economic development and environmental data of Jiangsu Province in 2005-2014 on the basis of theory of environment Kuznets curve in this article in order to analyze the relationship track between the economic growth and environmental pollution in Jiangsu Province. Moreover, the industrial structure should be adjusted, the investment in environmental protection should be increased and the mode of economic growth should be transformed in order to implement the healthy and sustainable development of economy in Jiangsu Province because emission of pollution in Jiangsu Province is still increasing.
\end{abstract}

Keywords-economic development; environmental pollution; per capita GDP; environment Kuznets curve

\section{INTRODUCTION}

The natural environment, which is deemed as the basis of economic growth, provides the necessaries for economic activities and absorbs and digests environmental pollution as a result of production and consumption. Would sustainable economic growth bring greater environmental pollution to one region or country, or be useful for improving the environmental quality? Many learners implement studies for it.

\section{LITERATURE REVIEW}

The Club of Rome had mentioned that "The population explosion, resource shortage, environmental pollution and ecological damage occur globally as a result of the traditional industrialization road since Industrial Revolution, and the economic growth could not last for a long time due to restriction of natural resources; and the rate of economic growth must be reduced to zero manually in order to protect the environment." in The Limits to Growth in 70s of the 21th century. While sustainable development theory developed in 80 s of the 21th century considered that the economic growth would not damage to the environment necessarily, and reduction of poverty would be indispensable for protecting the environment. Grossman and Krueger proved and analyzed the relationship between the environmental pollution level and the income per capita by using the data of the dust and the suspended particulate matter and acquired the conclusion that the environmental quality would be improved along with economic growth, rather than being worsened. Panayotou defined the relationship between the environment and the income per capita as the environment Kuznets curve (EKC) first, that is, the relationship that the emission of pollution would be worsened first and then reduced along economic growth, by using the theory proposed by Simon Kuznets in 1955 that the degree of income inequality would be worsened first and then weakened subsequently and would show the inverted U-shaped relationship along with economic growth. Afterwards, the relationship between the environment and the income was further verified in many literatures. Moreover, all kinds of pollutant indexes were taken as the explained variable, and the income level was taken as the explanatory variable to implement estimate in these literatures; and many research achievements were acquired by selecting different statistical methods, the environmental indexes and data to verify existence of inverted U-shaped relationship between all kinds of pollutants and the income level and the turning points of the inverted U-shaped relationship.

Study of environment Kuznets curve in China is later than that in other countries; the "Environment Kuznets Curve" was mentioned first in the domestic journal in 1997; then many researches of "Environment Kuznets Curve" were done along rapid economic development in China and rapid worsening of the environmental quality. The consistent conclusion has not been achieved in terms of existence of EKC hypothesis in China and empirical analysis of EKC curve shape. Li Fei, Duan Xianming, etc. verified and inspected the relationship between the environmental pollution and the economic growth throughout the country in 1985-2007 and 1997-2009 respectively; and the research result supported the EKC hypothesis. Pan Shan, etc. investigated the dynamic relationship between the environmental quality and economic growth by setting up generation overlapping model including the environmental quality, and the conclusion also supported the EKC hypothesis. However, some scholars doubted it; $\mathrm{Wu}$ Kaiya, etc. dis approved the inverted U-shaped EKC curve after 
studying the relationship between the economic growth and the environmental pollution in Anhui Province. Ding Jihong and Nian Yan found that the regular N-shaped curve relationship existed between the environmental pollution and per capita GDP after discussing the bidirectional relationship between the economic growth and the environmental pollution of Jiangsu Province in 1985-2006. Zhou Qian, etc. also found that the relationship between the economic growth and the environmental pollution in China was not in line with the traditional EKC curve; the economic growth had different effect to the different pollutants, and the inverted $\mathrm{N}$-shaped curve and N-shaped curve were involved; and the environmental pollution was worsened as a result of overall economic growth. The different scholars had the research conclusions of different function relationships between the environmental pollution and the economic growth as a result of differences in index selection and model setting. Therefore, the study of the dynamic model between the economic growth and the environmental pollution should be perfected in depth.

\section{INDEX SELECTION AND CORRELATION ANALYSIS}

Jiangsu Province is one of the provinces with the quickest economic development, the greatest general economic quantity and the most development potential in China, and produced GDP of RMB7011.64 billion which was ranked the second in 2015; however, the ecological environment is damaged seriously in Jiangsu Province and the environmental pollution problems are acute along continuous improvement of economic development, industrialization and urbanization of Jiangsu Province. Moreover, 2049 million tons of industrial wastewater was discharged, 109.2473 million tons of industrial solid wastes were generated, 1.0538 million tons of sulfur dioxide was discharged and 763.7 thousand tons of dust was discharged in Jiangsu Province in 2014.

Relevant pollutant emission indexes were selected in terms of the environmental quality by combining with the actual conditions of the economic development and environmental pollution in Jiangsu Province, that is, the discharge amounts of the industrial wastewater, the industrial waste gas and the industrial solid wastes. The per capita regional gross domestic product (per capita GDP) was selected as the economic development index which showed the economic development level and level of wealth of one region. The per capita GDP and the environmental quality index data of Jiangsu Province in 2005-2014 were selected to analyze the relationship between the economic development and the environmental pollution in this article, and all data was from Jiangsu Statistical Yearbook. Moreover, "Table I" for correlation of all indexes.

TABLE I. CORRELATION INSPECTION BETWEEN PER CAPITA GDP AND ENVIRONMENTAL POLLUTION IN JIANGSU PROVINCE

\begin{tabular}{|l|l|l|l|}
\hline & $\begin{array}{c}\text { Discharge } \\
\text { Amount of } \\
\text { Industrial } \\
\text { Waste Gas }\end{array}$ & $\begin{array}{c}\text { Discharge } \\
\text { Amount of } \\
\text { Industrial } \\
\text { Solid Wastes }\end{array}$ & $\begin{array}{c}\text { Discharge } \\
\text { Amount of } \\
\text { Industrial } \\
\text { Wastewater }\end{array}$ \\
\hline Correlation coefficient & $0.958^{* *}$ & $0.979^{* *}$ & $-0.934^{* *}$ \\
\hline Value of two-tailed test & 0.000 & 0.000 & 0.000 \\
\hline
\end{tabular}

The significant correlation exists between the economic development and three indexes of environmental pollution, and the significant probability values in the two-tailed tests are 0.000 , as shown in Table 1 . The correlation coefficient of the discharge amount of the industrial wastewater and the per capita GDP is -0.934 , which indicates the discharge amount of the industrial wastewater is reducing along with increasing of per capita GDP. Therefore, the econometric model between the environmental pollution index and the per capita GDP should be of full explanative significance.

\section{CONSTRUCTION AND REGRESSION ANALYSIS OF MODEL}

The linear function, the quadratic function, the cubic function, the exponential function and the logarithmic function are usually taken as the function model applied to description of the relationship between the economic development and the environmental pollution; and the linear function, the quadratic function and the cubic function were taken in the article to implementing fitting of the relationship between the per capita GDP and all indexes of the environmental pollution. Moreover, the relationship is as follows.

$$
\mathrm{Yi}=\beta 0+\beta 1 \mathrm{Xt}+\beta 2 \mathrm{Xt} 2+\beta 3 \mathrm{Xt} 3+\varepsilon \mathrm{t} \quad \mathrm{i}=1, \quad 2, \quad 3
$$

In the formula, $\mathrm{Yi}$ indicates the level of environmental pollution; Y1 indicates the discharge amount of the industrial waste gas; Y2 indicates the discharge amount of the industrial solid wastes; Y3 indicates the discharge amount of the industrial wastewater; $\mathrm{Xt}$ indicates the per capita GDP of th year; $\beta 0, \beta 1, \beta 2$ and $\beta 3$ indicate the coefficients of the explanatory variables; and $\varepsilon t$ indicates the random error term. Moreover, SPSS software was taken to implement the regression analysis for the per capita GDP and all indexes of the environmental pollution in this article, respectively; and see "Table II" and "Fig. 1", "Fig. 2", "Fig. 3" for the analysis results.

The model would be effective because the greater R2 is, the stronger the correlation of the variable would be. At the same time, the data of ten years from 2005 to 2014 with small amount of data was selected only in the article; therefore, the data of R2 after adjustment should be compared. Seen from the Table 2, R2(s) of the three models are close to each other in terms of the relationship between the discharge amount of the industrial waste gas and the per capita GDP; however, the quadratic model has the best fitting effect, and the $\mathrm{F}$ value thereof is greater than the cubic curve seen from the value of $\mathrm{R} 2$ after adjustment; further, the significance also is 0.000 , which indicates that the equation thereof is significant. R2(s) of the three models also are close to each other in terms of the relationship between the discharge amount of the industrial solid wastes and the per capita GDP, especially the quadratic model has tiny difference with the cubic model; however, R2 of the quadratic model is great after adjustment, and the $\mathrm{F}$ inspection value of the quadratic model is higher than that of the cubic model; and the significance thereof also is 0.000 , which indicates that the quadratic model has the better fitting effect. R2 of the cubic curve and the R2 after adjustment are greater than that of the quadratic model in terms of the relationship between the discharge amount of the industrial 
wastewater and the per capita GDP; and the F inspection value is higher than that of the quadratic model, and the significance is 0.000 ; therefore, the cubic curve has the better fitting effect.

TABLE II. COMPARISON OF FITTING RESULTS OF DIFFERENT TYPES OF CURVES

\begin{tabular}{|c|c|c|c|c|c|c|c|c|c|}
\hline & Model & $\mathbf{R 2}$ & $\begin{array}{c}\text { R2 after } \\
\text { Adjustment }\end{array}$ & $\begin{array}{c}\text { F Inspection } \\
\text { Value }\end{array}$ & Significance & $\begin{array}{l}\text { Constant } \\
\text { Term }\end{array}$ & $\begin{array}{l}\text { First } \\
\text { Term }\end{array}$ & $\begin{array}{c}\text { Quadratic } \\
\text { Term }\end{array}$ & $\begin{array}{l}\text { Cubic } \\
\text { Term }\end{array}$ \\
\hline \multirow{3}{*}{$\begin{array}{c}\text { Discharge } \\
\text { Amount of } \\
\text { Industrial } \\
\text { Waste Gas } \\
\end{array}$} & Linear function, & 0.936 & 0.928 & 116.617 & 0.000 & 1525.606 & 0.674 & & \\
\hline & Quadratic function & 0.954 & 0.940 & 71.934 & 0.000 & 16405.674 & 0.026 & $6.134 \mathrm{E}-6$ & \\
\hline & Cubic function & 0.959 & 0.939 & 47.031 & 0.000 & 41876.489 & -1.672 & $4.065 \mathrm{E}-5$ & $-2.172 \mathrm{E}-10$ \\
\hline \multirow{3}{*}{$\begin{array}{c}\text { Discharge } \\
\text { Amount of } \\
\text { Industrial } \\
\text { Solid Wastes } \\
\end{array}$} & Linear function, & 0.948 & 0.941 & 145.512 & 0.000 & 4317.420 & 0.087 & & \\
\hline & Quadratic function & 0.967 & 0.958 & 103.066 & 0.000 & 2331.319 & 0.174 & $-8.187 \mathrm{E}-7$ & \\
\hline & Cubic function & 0.968 & 0.953 & 61.179 & 0.000 & 3835.104 & 0.073 & $1.219 \mathrm{E}-6$ & $-1.283 \mathrm{E}-11$ \\
\hline \multirow{3}{*}{$\begin{array}{l}\text { Discharge } \\
\text { Amount of } \\
\text { Industrial } \\
\text { Wastewater }\end{array}$} & Linear function, & 0.931 & 0.922 & 107.360 & 0.000 & 325056.683 & -1.367 & & \\
\hline & Quadratic function & 0.938 & 0.920 & 52.889 & 0.000 & 305701.743 & -0.5245 & $-7.979 \mathrm{E}-6$ & \\
\hline & Cubic function & 0.972 & 0.959 & 70.290 & 0.000 & 434019.406 & -9.078 & 0.000 & $-1.094 \mathrm{E}-9$ \\
\hline
\end{tabular}

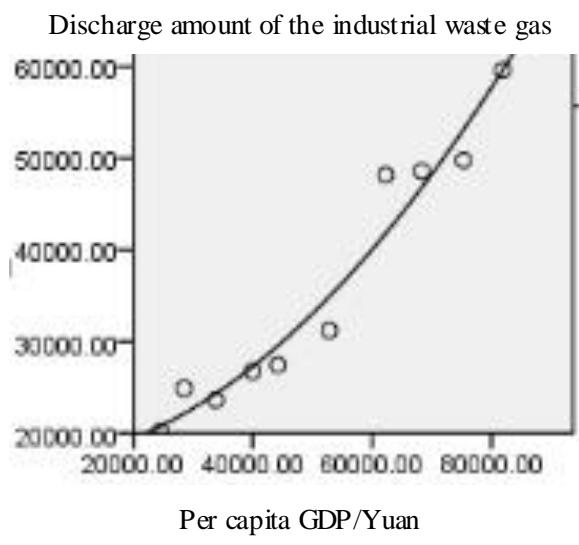

Fig. 1. Quadratic curve of the discharge amount of waste gas and the per capita GDP

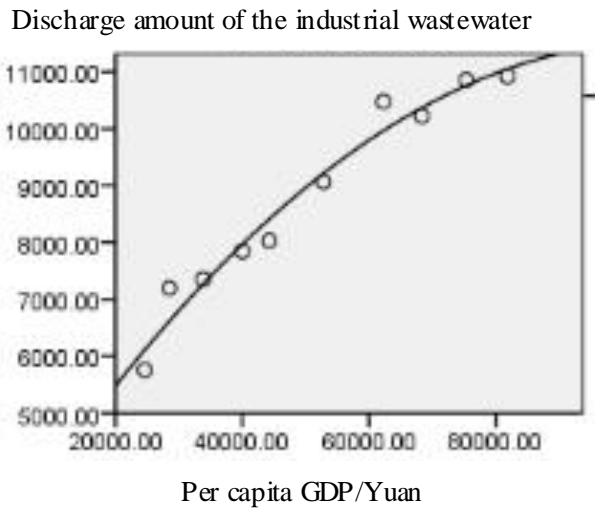

Fig. 2. Quadratic curve of the discharge amount of solid wastes and the per capita GDP

The discharge amount of the industrial waste gas is increasing continuously along rapid increasing of the economy in Jiangsu Province seen from the "Fig. 1"; but the significant characteristics of the six kinds of typical environment Kuznets curves are not displayed among the two aspects. The demand for the electric heat remains high in Jiangsu Province because of great economic aggregate and dense population; the total installed capacity and the thermal power generating units and the number of the units of the whole province rank top throughout the country; and tremendous amount of pollutants are discharged each year, which becomes the important factor affecting the quality of the atmospheric environment. At the same time, the pollutants discharged by the motor vehicle and all kinds of dust as a result of construction are increasing day by day along acceleration of economic development; thus, it is difficult to govern. The environmental governance cannot get effect instantly although the clear requirements were proposed for governance in allusion to sources of atmospheric pollution, such as the fired coal, the industry, the motor vehicle, the dust, etc.; and the time is required, and the investment of governance should be increased.

Seen from "Fig. 2", the environment Kuznets curve between the per capita GDP and the discharge amount of the industrial solid wastes shows the characteristics of the inverted U-shaped curve. Specifically, the discharge amount of the industrial solid wastes in Jiangsu Province was increasing quickly along increasing of per capita GDP in 2005-2007, and the environment was deteriorated; the speed of economic development in Jiangsu Province was slowed down as a result of the financial crisis from 2007 to 2009, and the discharge amount of the industrial solid wastes was increasing steadily; in order to relieve the effect of the subprime crisis to the economy, the Finance Department of Jiangsu Province increased the fund invested to the infrastructure construction from 2010 to 2014 so as to promote the economy in Jiangsu Province; therefore, the discharge amount of the industrial solid wastes was increasing quickly. The Jiangsu Government increases the strength of environmental governance continuously in recent years, RMB1.146 billion were invested for governance of the solid wastes and environmental protection in 2014; but RMB20 million was invested in 2005. However, there was a slight inadequacy in the investment 
strength for environmental protection compared with GDPRMB7 trillion of Jiangsu Province.

Seen from "Fig. 3", the characteris tic environment Ku znets curve between the per capita GDP and the discharge amount of the industrial wastewater in Jiangsu Province shows the characteristics of the inverted $\mathrm{N}$-shaped curve; and it is inseparable from the strengthened governance to the water pollution throughout the province mainly. The government of Jiangsu Province had issued the Decision on Strengthening Protection of Drinking Water Source first and proposed protection of the drinking water source and strengthening of construction of backup water source region while setting up the management system, including examination and approval of the drinking water source, division of the protection zone and procedure of backup water source region in 2008. The government of Jiangsu Province also started the standard construction of the central drinking water source in $2011.60 \%$ of the urban water source areas meeting the standard have been constructed throughout the whole province so far, and the emergency backup water source or the double-source water supply has been constructed in $80 \%$ of the cities and counties throughout the whole province. Es pecially, the government of Jiangsu Province had issued the strict Control Regulations on water pollution of Lake Taihu in 2007 after cyanobacteria bloom crisis in Lake Taihu in order to strengthen inspection of the high incidence area of water pollution, clamp down the production enterprises of pollutants affecting the safety of the water source and take the measures, such as closing down, merging, shifting to the different line of production, etc. for these enterprises; therefore, the discharge amount of the water polluted was slowed down throughout the whole province. The government of Jiangsu Province had completed 1435 water pollution emissions-reduction projects in 2014; the daily sewage treatment capacity was increased for $800000 \mathrm{~m} 3 /$ day in the urban area; and the actual annual sewage treatment capacity of the urban sewage treatment plant could achieve 3.83 billion cubic meters. Moreover, the discharge amount of the sewage of the whole province was reducing year by year.

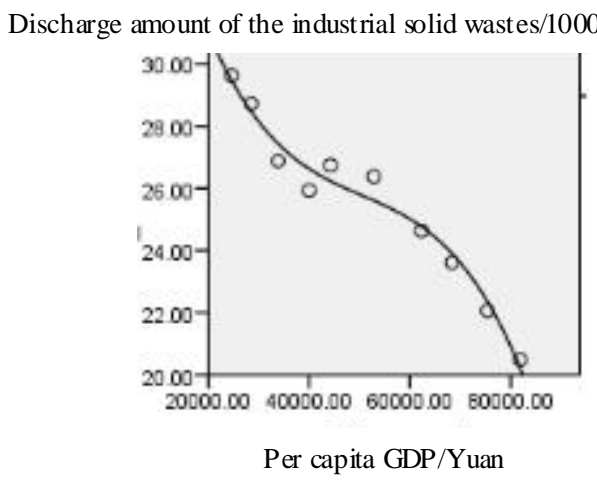

Fig. 3. Quadratic curve of the discharge amount of wastewater and the per capita GDP

\section{CONCLUSION}

The linear curve, the quadratic curve and the cubic curve were selected to implement fitting in accordance with relevant data of the per capita GDP and the environmental quality indexes of Jiangsu Province from 2005 to 2014, wherein the characteristics of the typical environment Kuznets curve was not displayed among the discharge amount of the industrial waste gas and the per capita GDP; the inverted U-shaped curve was displayed between the output of the industrial solid wastes and the per capita GDP; and the inverted N-shaped curve was displayed between the discharge amount of the industrial wastewater and the per capita GDP. Moreover, the discharge amounts of the waste gas and the solid wastes were increasing continuously along with increasing economy of Jiangsu Province; but the discharge amount of the waste water was reducing.

The environment Kuznets curve refers to the empirical relationship acquired by using the per capita GDP and the variable-environmental quality, and cannot be taken to explain the essence among the two aspects. Economic growth would not solve or imp rove the environmental problems itself; the concept of "Pollution first, treatment later" shall not be acceptable; or the level of pollution shall not be reduced automatically and the environmental quality shall not be improved automatically when the economic income is improved. Jiangsu is not only one of the major provinces of economy, but one of the major provinces of population. The environmental governance should not only be balanced with the economic development, but is the crucial factor affecting the living quality for the residents in Jiangsu Province. Therefore, we should do the following points in order to carry out the sustainable development of the ecological environment in Jiangsu Province: Increase investment to the environmental governance and improve the control strength of the region polluted while implementing innovation of environmental protection technology and quickening completion of annual emission-reduction task; deepen the reform of environmental protection system and expand international cooperative exchanges of environmental protection while delegating the authority to administration examination and approval for the environmental protection project and promoting public participation in the environmental protection activities; change the current situation of industrial pollution at its source by adjusting the industrial structure and the intra-industry industrial structure actively and transforming the economic growth mode; and improve the environment monitoring and early warning ability by strengthening the law enforcement of environment and perfecting the environment emergency response and guarantee system.

\section{REFERENCES}

[1] Li Fei, Dong Suocheng, Li Zehong. Re-inspection of Relationship of Economic Growth and Environmental Pollution in China -- Panel Coint egration Test on the Basis of Provincial Data [J]. Journal of Natural Resources, 2009(1 1): 1912-1919.

[2] Duan Xianming, Xu Min. Empirical Analysis of Relationship of Economic Growth and Environmental Pollution in China on the Basis of PVAR Model [J]. China Population, Resources and Environment,2012(12): 136-139.

[3] Pan Shan, Ma Song. Environmental Quality and Economic Growth: Theoretical Analysis in Presence of Generation Overlapping Model [J]. Ecological Economy, 2013(4):33-38 
[4] Ding Jihong, Nian Yan. Analysis of Relationship of Economic Growth and Environmental Pollution--Taking Jiangsu Province as An Example [J]. Nankai Economic Studies,2010 (2):64-79.

[5] Wang Min, Huang Ying. Environmental Pollution and Economic Growth in China [J]. China Economic Quarterly, 2015(1):557-578.

[6] Zhou Qian, Hu Huiyuan. Empirical Test of Effect of Economic Growth in China to Environmental Quality [J]. Statistics and Decision, 2014 (1):120-124.

[7] Wu Kaiya, Chen Xiaojian. Study on the Relationship between Economic Growth and Environmental Degradation of Anhui Province [J]. Chongqing Environmental Science, 2003(6):9-11.

[8] Zhong Maochu, Zhang Xuegang. Summary about the Critique of Environmental Kuznets Curve Theory and Study [J]. China Population, Resources and Environment,2010 ( 2): 62-67. 